\title{
Safety, Efficacy and Acceptability of Early First Trimester Abortion using Oral Mifepristone and Sublingual Misoprostol
}

\author{
Deepak Shrestha, ${ }^{1}$ Shreyashi Aryal, ${ }^{1}$ Binita Sharma ${ }^{1}$ \\ 'Department of Obstetrics and Gynecology, Lumbini Medical College and Teaching Hospital, Pravash, Tansen, \\ Palpa, Nepal.
}

\section{ABSTRACT}

\begin{abstract}
Background:With the legalization of medical abortion in Nepal, mifepristone-misoprostol combination via different routes has been widely used for early abortion. This study aims to evaluate the efficacy and acceptability of 200 milligrams mifepristone orally followed by 800 micrograms sublingual misoprostol in outpatient setting.

Methods: It was an open-label prospective study conducted in outpatient department of a tertiary hospital over a period of 13 months. Clients upto nine weeks of pregnancy were enrolled. 200 milligrams of mifepristone orally followed by 800 micrograms of misoprostol sublingually 36 to 48 hours later were prescribed. They were followed up in 14 days sonologically or verbally through telephone. Side effects and satisfaction to the regimen were assessed through acceptability questionnaire. Mann-Whitney U test was used for analyzing categorical data.

Results: A total of 47 clients were enrolled. The mean age and gestational age were 29.38 years $(\mathrm{SD} \pm 5.914)$ and 6.2 weeks $(\mathrm{SD} \pm 1.28)$ respectively. The commonest indications for termination were completed family and unwanted pregnancy $(40.4 \%$ each). The average duration of bleeding was 5.76 days (SD \pm 3.61$)$. Abdominal cramping was the most common side effect (95.7\%). The least acceptable parameter was the bleeding time (80.9\%). For 97.9\% clients, the adverse effects were acceptable. The overall success rate of the regimen was $87.2 \%$.

Conclusions: With a comparable success rate to vaginal use, home based sublingual use of misoprostol in low resource settings offers an acceptable and cost effective alternative for medical abortion upto nine weeks of pregnancy. Lesser gestational age is a useful predictor for successful abortion.
\end{abstract}

Keywords: abortion; mifepristone; misoprostol; sublingual; termination.

\section{INTRODUCTION}

Unsafe abortion is a major health issue. ${ }^{1}$ In 2014 alone, out of an estimated 323,000 abortions performed in Nepal, only $42 \%$ were provided legally by authorized service providers. ${ }^{2}$

With the $11^{\text {th }}$ amendment in Nepal Criminal Code in March 2002, abortion law was liberalized under certain circumstances. ${ }^{3}$ Studies have since been conducted to evaluate the efficacy of different regimens of mifepristone and misoprostol. World Health Organization recommends 200 milligrams $(\mathrm{mg})$ mifepristone orally followed by 800 micrograms $(\mu \mathrm{g})$ buccal misoprostol for early abortion upto 63 days of gestation. ${ }^{4}$

Most literature have studied the vaginal use of misoprostol. Published studies regarding sublingual use of misoprostol in our set up are scarce. This study aims to assess the efficacy, safety and acceptability of mifepristone orally and misoprostol sublingually for early first trimester abortion.

\section{METHODS}

It was an open-label prospective clinical study conducted in Out Patient Department (OPD) of Lumbini Medical College and Teaching Hospital over a period of 13 months from 16th December, 2016 to 15th January, 2018. Ethical clearance was obtained from the Institutional Review Committee.

Clients upto nine weeks of pregnancy requesting medical abortion were enrolled after obtaining consent. Gestational age (GA) was calculated from the last menstrual period (LMP) for regular cycles and from
DOI: http://dx.doi.org/10.3126/

jnhrc.v16i3.21422
Correspondence: Deepak Shrestha, Department of Obstetrics and Gynecology, Lumbini Medical College and Teaching Hospital, Pravash, Tansen, Palpa, Nepal. Email: thecups814@gmail.com, Phone: +9779843225408. 
ultrasonogram (USG) for irregular cycles or mistaken date. Hemoglobin level, blood group, platelets count and USG were done. Those with history of bronchial asthma, ectopic pregnancy and severe anemia were excluded from the study.

On day 1, mifepristone (one tablet of $200 \mathrm{mg}$ ) was given to be swallowed under supervision. She was instructed not to take any food for next two hours. On day 3, four tablets of $200 \mu \mathrm{g}$ misoprostol ( $800 \mu \mathrm{g}$ total) were given to be placed sublingually after 36 to 48 hours of mifepristone intake at home. She was instructed to retain the tablets for half an hour sublingually and spit out the residue. Possible side effects were explained. An analgesic was given on as required basis.

The clients were followed up in two weeks for clinical and sonological evaluation for completion of abortion and any side effects. Those unable to return were enquired through telephone. Clients with persistent /heavy bleeding or substantial amount of retained products of conception (POC) were surgically evacuated. Those reporting heavier or prolonged bleeding than usual menstrual cycle were considered having excessive bleeding. Those with bleeding comparable to their menstruation were labeled as having normal bleeding.

The primary outcome of interest was successful abortion. It was defined as expulsion of the POC without the need for aspiration. Patients requiring aspiration for retained POC, ongoing pregnancy or heavy bleeding were considered unsuccessful abortion.

The data were entered and analyzed using Statistical Package for Social Sciences (SPSS ${ }^{T M}$ ) version 21. Quantitative data were presented with mean \pm SD and qualitative data by frequency and percentages. Categorical data was analyzed using Mann-Whitney $U$ test. $\mathrm{P}$ value $<0.05$ was considered significant.

\section{RESULTS}

A total of 22,800 patients were entertained in OPD during the study period. Out of 49 patients enrolled, two were lost to follow up.

The mean age of the study population was 29.38 years $(\mathrm{SD}= \pm 5.91)$. The average $\mathrm{GA}$ was 6.2 weeks $(S D= \pm 1.28)$. Majority of the clients were between 5 to 7 weeks GA (Table 1).

The number of clients terminating the pregnancy for unwanted pregnancy and completion of family was same (19 each). Two clients opted medical abortion (MA) in order to continue their education. Out of seven in the 'others' category, two underwent MA for short spacing while one had to undergo percutaneous nephrolithotripsy (Table 2).

\section{Table 1. Socio-demographic characteristics ( $N=47)$}

\begin{tabular}{|c|c|c|c|c|}
\hline $\begin{array}{l}\text { Character- } \\
\text { istics }\end{array}$ & $\begin{array}{r}\text { Mean } \\
(\text { SD) }\end{array}$ & $\begin{array}{r}\text { Frequency } \\
(\%)\end{array}$ & Median & $\begin{array}{r}\text { Range } \\
\text { (minimum- } \\
\text { maximum) }\end{array}$ \\
\hline Age (years) & $\begin{array}{r}29.38 \\
(+5.914)\end{array}$ & & & \\
\hline $\begin{array}{l}\text { Gestational } \\
\text { age } \\
\text { (weeks) }\end{array}$ & $\begin{array}{r}6.2 \\
( \pm 1.28)\end{array}$ & & & \\
\hline $\begin{array}{l}4.1-5.0 \\
\text { weeks }\end{array}$ & & 9 (19.14\%) & & \\
\hline $\begin{array}{l}5.1-6.0 \\
\text { weeks }\end{array}$ & & $\begin{array}{r}13 \\
(27.65 \%)\end{array}$ & & \\
\hline $\begin{array}{l}6.1-7.0 \\
\text { weeks }\end{array}$ & & $\begin{array}{r}12 \\
(25.53 \%)\end{array}$ & & \\
\hline $\begin{array}{l}7.1-8.0 \\
\text { weeks }\end{array}$ & & 9 (19.14\%) & & \\
\hline $\begin{array}{l}8.1-9.0 \\
\text { weeks }\end{array}$ & & 4 (8.5\%) & & \\
\hline Gravidity & & & 3 & $5(1-6)$ \\
\hline Parity & & & 2 & $5(0-5)$ \\
\hline
\end{tabular}

Table 2. Indication for terminations ( $N=47)$

\begin{tabular}{lll} 
Indication & Frequency & Percentage \\
\hline Family completed & 19 & $40.4 \%$ \\
Unwanted pregnancy & 19 & $40.4 \%$ \\
Studies/profession & 2 & $4.3 \%$ \\
Others & 7 & $14.9 \%$
\end{tabular}

The mean duration for onset of bleeding was 1.61 days $(S D \pm 1.31)$ while the mean total duration of bleeding was 5.76 days $(S D \pm 3.61)$. One woman had bleeding lasting upto 15 days.

The overall success of this regimen to effect a complete abortion was $87.2 \%(95 \% \mathrm{Cl} 78.7 \%-95.2 \%)$ (Table 3). Clients at or less than six weeks GA had higher success rate $(100 \%)$ than those at higher GA.

Mean GA among the complete abortion group was 6.06 weeks ( $S D= \pm 1.28$ ) and that among the retained POC group was 7.15 weeks $(S D= \pm 0.91)$. This difference in mean was compared with Mann-Whitney $U$ test and was found to be statistically significant (Mann-Whitney $\mathrm{U}=186.000, \mathrm{p}=0.044, \mathrm{~N}=47$ ). Women with lesser GA were more likely to result in complete abortion. The difference in the outcome of abortion (complete abortion vs retained POC) in GA from 6.1 to 7.0 weeks (Mann-Whitney $U=13, p=1.000, \quad n=12$ ), 7.1-8.0 weeks (Mann-Whitney $U=6, p=1.000, n=9$ ) and 8.1 to 9.0 weeks (Mann-Whitney $U=1.5, p=1.000, n=4$ ) was not significant.

The most adopted method of contraception after MA was OCPs $(21.3 \%)$. One client underwent permanent sterilization. Nineteen clients $(40.4 \%)$ did not use any form of contraception for various reasons (Table 4). 
Table 3. Gestational age wise outcomes of MA: $n(\%)(N=47)$

\begin{tabular}{|c|c|c|c|c|c|c|c|c|c|}
\hline \multicolumn{2}{|c|}{ GA (weeks) } & $\leq 5$ & $5.1-6.0$ & $6.1-7.0$ & $7.1-8.0$ & $8.1-9.0$ & $\begin{array}{l}\text { Mean GA } \\
\text { (SD) }\end{array}$ & Total (\%) & $95 \% \mathrm{Cl}$ \\
\hline \multirow{2}{*}{$\begin{array}{l}\text { USG } \\
\text { finding }\end{array}$} & $\begin{array}{l}\text { Complete } \\
\text { abortion }\end{array}$ & $9(100)$ & $13(100)$ & $9(75)$ & 7 (77.78) & $3(75)$ & $6.06(1.28)$ & $41(87.2)$ & $\begin{array}{l}78.7- \\
95.2\end{array}$ \\
\hline & Retained POC & $0(0)$ & $0(0)$ & $3(25)$ & $2(22.22)$ & $1(25)$ & $7.15(0.91)$ & $6(12.8)$ & $4.8-21.3$ \\
\hline \multicolumn{2}{|c|}{ Mann- Whitney U } & * & $\dagger$ & 13 & 6 & 1.5 & 186 & & \\
\hline \multicolumn{2}{|l|}{$p$ value } & & & 1.000 & 0.889 & 1.000 & 0.044 & & \\
\hline
\end{tabular}

Abdominal cramping (95.7\%) was the most frequently complained symptom while gastrointestinal disturbance (6.3\%) was the least common (Table 5).

Table 4. Choice of contraception after MA ( N=47).

\begin{tabular}{|c|c|c|}
\hline Contraception & Frequency & (percentage) \\
\hline OCPsł & & $10(21.3 \%)$ \\
\hline IUCD§ & & $8(17 \%)$ \\
\hline Jadelle & & $5(10.6 \%)$ \\
\hline Depo Provera & & $4(8.5 \%)$ \\
\hline Permanent sterilization & & $1(2.1 \%)$ \\
\hline None & & $19(40.4 \%)$ \\
\hline $\begin{array}{l}\text { ¥OCPs: oral contracept } \\
\text { contraceptive device }\end{array}$ & pills, §IUCD: & intrauterine \\
\hline
\end{tabular}

Table 5. Side effects profile.

\begin{tabular}{lr} 
Side effect & Frequency(percentage) \\
\hline Nausea/vomiting & $4(8.5 \%)$ \\
\hline Abdominal cramping & $45(95.7 \%)$ \\
Gastrointestinal disturbance & $3(6.3 \%)$ \\
Heavy bleeding & $12(25.5 \%)$ \\
\hline
\end{tabular}

Thirty-one clients $(66 \%)$ had normal amount of bleeding after MA, 14 clients $(29.7 \%)$ reported excessive bleeding and two clients had minimal bleeding.

The least acceptable parameter was the bleeding time (80.9\%). Forty-three clients $(91.5 \%)$ were willing to choose similar treatment in future and 45 (95.7\%) clients would recommend similar treatment to others. This showed $90-95 \%$ clients were satisfied with the overall efficacy of the regimen (Table 6).

\begin{tabular}{ll}
$\begin{array}{ll}\text { Table 6. Clients' acceptability to MA. } \\
\text { Acceptability parameters }\end{array}$ & $\begin{array}{l}\text { Frequency } \\
(\%)\end{array}$ \\
\hline Bleeding time acceptable & $38(80.9 \%)$ \\
\hline Abdominal pain acceptable & $45(95.7 \%)$ \\
\hline Adverse effects acceptable & $46(97.9 \%)$ \\
\hline Choose similar treatment in future & $43(91.5 \%)$ \\
\hline Recommend similar treatment to others & $45(95.7 \%)$ \\
\hline
\end{tabular}

\section{DISCUSSION}

The mean age of the clients (29.38 years) in our study was similar to a pilot study (27 years) done in Nepal. ${ }^{5}$ A French study reported the mean age of 27.6 years. ${ }^{6}$ Smith et al reported the median age of 24 years in 1001 participants. ${ }^{7}$ In the face of rising teenage pregnancies, these data imply that majority of women seeking MA in this region are still within the reproductive age group. The slightly higher mean age in our study reflects that most of the terminations were done for second and third conceptions.

The median gravidity and parity were comparable to other studies. In a pilot study, 30\% clients were gravida second and 30\% were gravida four and above. ${ }^{5}$ The median gravidity was two in Smith et al's study. ${ }^{7}$ This suggests most of the couples had completed family. Only three clients in our study were primigravida; two with unwanted pregnancies while one wanted termination to continue her education. These findings indirectly point towards the inadequacy of contraception practice. The use of long acting reversible contraceptives or permanent sterilization is evidently low. One important aspect of this study was therefore to encourage clients to adopt contraception after confirmation of completion of abortion.

The mean gestational age $(6.2 \pm 1.28$ weeks $)$ at termination was similar to other studies. ${ }^{5}$ In the study by Smith et al, $65.3 \%$ of the study population were $<8$ weeks gestation. ${ }^{7}$ In our study, $46.79 \%$ of the clients were at or less than six weeks of gestation. This is because most of them, being unwanted pregnancies, were decided for termination as soon as confirmed. Only four cases out of 47 were beyond eight weeks.

Indication-wise, completed family and unwanted pregnancy accounted for the same percentage (40.4\%). Completed family was the most common reason $(53.3 \%)$ for termination in another study as well. ${ }^{5}$

Several studies have studied the vaginal use of misoprostol. ${ }^{1,5,8}$ Our study evaluated the efficacy, side effects and acceptability of its sublingual use. 
This allowed women to maintain the privacy of the procedure, apparently a big concern in our part of the world. Avoiding hospital admission and stays, this homebased regimen significantly reduces the total cost of the procedure. Cost effective regimens in low-income countries are an advantage itself. Administration of misoprostol by sublingual rather than oral route has been shown to have less failure rate as well. ${ }^{9}$

In a secondary analysis of a randomized controlled trial consisting 731 participants, home-use of misoprostol for early medical abortion was found as effective and acceptable as clinic use, in low resource settings. ${ }^{10}$

The success rate of the regimen in our study (87.2\%) is comparable to another study $(86.7 \%) .{ }^{5}$ Other studies have reported a relatively higher success rate of $92.6 \%$ and $97.7 \% .^{1,11}$ The complete abortion rate in Smith et al's study was $90 \%$ in $57-63$ days GA group and $94.9 \%$ in $<56$ days GA group. ${ }^{7}$ Only six clients out of 47 in this study had evidence of retained POC in follow up scans. Five of them underwent subsequent aspiration. One was treated with second dose of misoprostol as she refused for surgical evacuation. A study comparing the efficacy of two pill sublingual misoprostol outpatient regimen through 70 days GA reported the success rate of $94.8 \%$ in the 57-63 days group. ${ }^{12}$ This two pill regimen opens up possibility of further research with low dose misoprostol in our set up as well. The lower success rate in our study could be because of smaller sample size. Moreover, unlike in other studies, we did not use a second dose of misoprostol for retained POC except in one. ${ }^{11}$

The success rate of MA is seen to decrease with increasing GA (Table 3 ). There is higher success rate (100\%) in $\leq 6$ weeks $G A$ than in 6.1 to 7.0 weeks $G A(75 \%)$, 7.1 to 8.0 weeks GA $(77.78 \%)$ or 8.1 to 9.0 weeks GA (75\%). Statistical analysis showed significant difference between the means of GA of complete abortion and retained POC categories. Women with less GA were therefore more likely to achieve complete abortion. However, in week by week analysis, there was no significant difference in the 6.1 to 7.0 weeks GA, 7.1 to 8.0 weeks GA and 8.1 to 9.0 weeks GA groups. Thus our study showed that clients at $\leq 6$ weeks of GA were likely to undergo complete abortion. At higher GA, chance of having complete abortion was not statistically different from having incomplete abortion. This finding agrees with the study by Gatter $M$ et al which reported those at 36 to 42 days of gestation had greater odds of success, whereas those at 50 to 56 days and 57 to 63 days had lower odds of success in comparison to the reference group (43 to 49 days). ${ }^{11}$ In Smith et al's study too, significantly higher complete abortion rate in $<56$ days GA group than in 57-63 days GA group $(94.9 \%$ vs $90 \%, p=0.02$ ) was reported. ${ }^{7}$ This is also supported by another study with a $50 \%$ higher odds of medical abortion failure in groups that had a higher proportion $(>25 \%)$ of women in the ninth week of pregnancy. ${ }^{13}$ As there is no significant decrease in success rate between 8th and 9th weeks GA group, this opens up possibilities of extending the same regimen upto 10 weeks GA with not much change in success rate. This has been explored in some studies. ${ }^{12}$

In our study, $40.4 \%$ clients did not use any contraception for various reasons. OCP was the most commonly used method (21.3\%). A majority of clients thus still remains uncounselled or unconvinced for contraception use after abortion.

Abdominal cramping was the most common side effect (95.7\%). This suggests clients undergoing MA will be benefitted by routine analgesics rather than on required basis. Nausea and/or vomiting in our study was found in $8.5 \%$ of the clients. Gastrointestinal disturbance was the least common side effect (6.3\%). All the adverse effects experienced in our study were after the use of misoprostol. No such side effects were reported after mifepristone ingestion.

In this study, 14 clients $(29.8 \%)$ experienced excessive bleeding. Majority (66\%) had normal bleeding. One participant with retained POC had prolonged bleeding upto 15 days.

The acceptability questionnaire showed the least acceptable parameter was bleeding time $(80.9 \%)$. Most of those having excessive bleeding were not satisfied with the overall bleeding time. Overall adverse effects were acceptable to $97.9 \%$ women and $95.7 \%$ were willing to recommend the same treatment to others. Clients opting the same treatment in future were $91.5 \%$. This proved that more than $90 \%$ clients were satisfied with the overall efficacy of the regimen. The overall acceptance and satisfaction was high because the clients could entirely avoid surgical intervention with good success rate. The confidentiality conferred by this outpatient regimen and avoidance of vaginal insertion were also responsible for its high acceptance rate.

Smaller sample size of this study is a notable limitation. Follow up enquires through telephone were comparatively less authentic. The study did not evaluate the induction to abortion interval as well.

\section{CONCLUSIONS}

With the legalization of abortion upto 12 weeks of pregnancy, an increasing number of women are seeking services for medical termination of pregnancy. A combined regimen of mifepristone and misoprostol 
provides an easier and non-invasive method of termination for upto nine weeks of pregnancy. This study highlighted the fact that sublingual use of misoprostol results in a comparable success rate to vaginal use with added benefit of outpatient use. Lesser GA was a key predictor for successful abortion. The acceptability was also very satisfactory. The study also emphasizes the cost effectiveness of the regimen in low-income countries. However, further studies with larger sample size evaluating the cost effectiveness and induction to abortion intervals are suggested.

\section{ACKNOWLEDGEMENTS}

We are thankful to Dr Sebina Baniya for help in data acquisition.

\section{REFERENCES}

1. Shrivastava V. Safety, efficacy and acceptability of medical abortion with mifepristone and misoprostol in Nepalese women. Nepal Journal of Obstetrics and Gynaecology. 2007 Nov;2(2):54-8.[Full Text Link] [DOI]

2. Puri M, Singh S, Sundaram A, Hussain R, Tamang A, Crowell M. Abortion incidence and unintended pregnancy in Nepal. Int Perspect Sex Reprod Health. 2016;42(4): 197. [PubMed] [DOI]

3. Nepal Ministry of Health. National Safe Abortion Policy. Kathmandu, Nepal: 2002.[Full Text Link]

4. World Health Organization. Safe Abortion: Technical and Policy Guidance for Health Systems. 2nd ed. Geneva: WHO; 2012.[Full Text Link]

5. Shrestha A, Sedai LB. The Efficacy and Acceptability of Medical Abortion of Less Than 63 Days Gestation in Chitwan. Journal of Chitwan Medical College. 2012: 1(2); 1-4[Full Text Link]

6. Nisand I, Bettahar K. Medical management of unwanted pregnancy in France: modalities and outcomes. The aMaYa study. Eur J Obstet Gynecol Reprod Biol. 2015;184:13-8. [Science Direct] [DOI]

7. Sanhueza Smith P, Peña M, Dzuba IG, Martinez ML, Peraza AG, Bousiéguez M, and et al. Safety, Efficacy and Acceptability of Outpatient Mifepristone-misoprostol Medical Abortion Through 70 Days Since Last Menstrual Period in Public Sector Facilities in Mexico City. Reproductive Health Matters. 2014;22(sup44):75-82. [DOI] [Full Text Link]
8. Shrestha A, Sedhai LB. A Randomized Trial of Hospital Vs Home Self Administration of Vaginal Misoprostol for Medical Abortion. Kathmandu Univ Med J 2014;47(3):185-9.[Full Text Link]

9. Kulier R, Gulmezoglu AM, Hofmeyr GJ, Cheng LN, Campana A. Medical methods for first trimester abortion. Cochrane Database Syst Rev. 2004 Jan 1;2(2). [Link]

10. Iyengar K, Klingberg-Allvin M, Iyengar SD, Paul M, Essén B, Gemzell-Danielsson K. Home use of misoprostol for early medical abortion in a low resource setting: secondary analysis of a randomized controlled trial. Obstet Gynecol Scand. 2016;95(2):173-81.[Full Text Link][DOI]

11. Gatter M, Cleland K, Nucatola D L. Efficacy and safety of medical abortion using mifepristone and buccal misoprostol through 63 days. Contraception. 2015; 91(4):269-73[Science Direct] [DOI]

12. Bracken H, Dabash R, Tsertsvadze G, Posohova S, Shah M, Hajri S, et al. A two-pill sublingual misoprostol outpatient regimen following mifepristone for medical abortion through 70 days' LMP: a prospective comparative openlabel trial. Contraception. 2014;89(3):181-6. Science Direct][DOI]

13. Raymond EG, Shannon C, Weaver MA, Winikoff B. Firsttrimester medical abortion with mifepristone $200 \mathrm{mg}$ and misoprostol: a systematic review. Contraception. 2013;87(1):26-37.[Science Direct][DOI] 